\title{
DESARROLLAR LA COMPETENCIA REFLEXIVA EN LA EDUCACIÓN SUPERIOR. DIEZ PROPUESTAS PARA EL AULA UNIVERSITARIA
}

Ángeles Domingo Roget

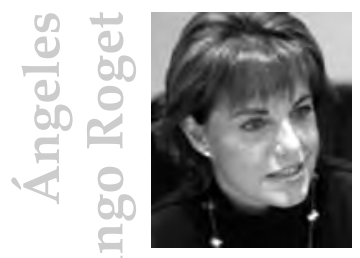

Posgrado Europeo «Horizonte Bolonia» de Nuevas metodologías de formación Universitaria. Posgrado en Desarrollo de competencias directivas, MDB, Barcelona. Doctorado en Pedagogía, Universidad Internacional de Catalunya. Veinte años de experiencia docente en diferentes niveles de enseñanza media y enseñanza superior. Licenciada en Pedagogía, Universidad de Barcelona. Se ha dedicado a las Ciencias de la Educación, especialmente a la docencia, la Didáctica y a la investigación. Ha participado en proyectos universitarios de formación reflexiva y en pruebas piloto de experimentación de estudios en línea con EEES. Actualmente participa también en formación de metodologías docentes universitarias. Es experta en Práctica reflexiva; Aprendizaje experiencial, y Practicum universitarios.

Correo electrónico: [adomngor@gmail.com].

\section{RESUMEN}

Las conclusiones de esta investigación realizada a lo largo del curso 2008 en las aulas universitarias de la Facultad de Educación de la Universidad Internacional de Cataluña, se sitúan en un marco paradigmático crítico-reflexivo - superado el conocimiento por reproducción o transmisión- y apuestan con determinación por la formación reflexiva de los futuros docentes. Las propuestas de desarrollo de la competencia reflexiva en el aula universitaria son adecuadas para todas las titulaciones, aunque mi experiencia se circunscribe a titulaciones de formación docente. Las diez propuestas que se presentan propician, en 
cada estudiante, la construcción de su proyecto personal y promueven la competencia reflexiva y activa en los escenarios profesionales, reforzándose de este modo la profesionalización docente. Fomentar la competencia reflexiva durante la formación inicial universitaria ha producido resultados de profesionalización en los docentes egresados de la Universidad, mismos que podemos sintetizar así:

- Mayor capacidad de resolver situaciones prácticas como profesionales expertos.

- Articulación más profunda en su quehacer docente de teoría y práctica, conocimiento formal y práctico, criterio científico y compromiso ético y social.

- Mayor preparación metodológica para innovar e investigar a partir de su trabajo docente.

Palabras clave: formación reflexiva en el aula universitaria; desarrollo de la competencia reflexiva; profesionalización; estrategias para enseñar la reflexividad; formación universitaria; propuestas docentes para la reflexividad.

\section{ABSTRACT}

The findings of this research conducted throughout the course in 2008 the university classrooms in the Department of Education, International University of Catalonia, located in a critical-reflexive paradigm, overcoming the reproduction and transmission of knowledge and determination to bet with reflexive training of future teachers. Proposals for the development of reflexive competence in the classroom are appropriate for all university degrees but my experimentation has been confined deformation degrees in teaching. The 10 proposals submitted to each provide students the construction of its project staff and promotes competition thoughtful and active professionals in the scenarios thus reinforcing the professional teachers. Encouraging reflective competence during initial training college has produced these results at professional teachers graduated from the University we can summarize as follows:

- Increased ability to solve practical and professional experts. 
- Articulation deeper in your work of teaching theory and practice, formal knowledge and practical, scientific and ethical and social.

- Greater preparedness to innovate and research methodology from his work teaching.

Keywords: training in the university classroom reflexive; development of reflexive competence; professionalization; strategies for teaching reflexivity; training college; proposals for teaching reflexivity.

\section{DE LA REFLEXIÓN OCASIONAL A LA REFLEXIÓN METODOLÓGICA}

La capacidad de reflexión se nos presenta, en principio, como una característica de la persona, inherente a su condición humana. Sabemos, y así lo corrobora la experiencia propia, que el ser humano ejercita su capacidad reflexiva espontáneamente, sin precisar de un aprendizaje explícito o formal. En términos generales decimos que el ser humano es capaz de reflexionar y pensar de forma innata.

Sin embargo, para afrontar el estudio de la cuestión es preciso apuntar la diferencia existente entre la forma habitual de reflexionar del ser humano y la denominada "reflexión metodológica». Aunque una se apoya en la otra, no son realidades iguales ni expresiones de significado unívoco.

Si bien es cierto que la reflexión en el ser humano es una realidad natural y espontánea, la competencia reflexiva (CR) es, por el contrario, una actividad aprendida que requiere un análisis metódico, regular, instrumentado, sereno y efectivo; la CR sólo se adquiere con un entrenamiento voluntario e intensivo. La reflexión es, ordinariamente, una actividad mental natural y ocasional; en cambio, la CR es una postura intelectual metódica ante la práctica, requiere una actitud metodológica y una intencionalidad por parte de quien la ejercita. Algunas de sus diferencias más obvias se muestran en el siguiente cuadro comparativo: 


\section{NOTAS DIFERENCIALES}

\begin{tabular}{|l|l|}
\hline REFLEXIÓN & REFLEXIóN METODOLóGICA \\
\hline Innata & Aprendida \\
\hline Espontánea & Metódica \\
\hline Instantánea & Sistemática \\
\hline Natural & Instrumentada \\
\hline Improvisada & Premeditada \\
\hline Casual & Intencional \\
\hline
\end{tabular}

Aunque expusimos que la reflexión es una operación natural de la inteligencia humana, resulta claro que para que una persona actualice esta capacidad en potencia, necesita desarrollar ciertos hábitos reflexivos (curiosidad, disciplina mental...), pues éstos no se crean espontáneamente. Se requiere un compromiso con la reflexión puesto que una simple disposición para la reflexión puede convertirla en algo esporádico y superficial.

Profundizaremos ahora en el concepto de CR, analizando sus orígenes, naturaleza, finalidad, etcétera.

A modo de información preliminar, distinguiremos la CR profesional de la CR del estudiante universitario. Nuestro estudio se centrará concretamente en la segunda modalidad, puesto que nuestra investigación pretende estudiar cómo introducirla, enseñarla y comprobar sus resultados formativos en los universitarios, cuando aún se encuentran en el período de su formación inicial universitaria; su vivencia e inmersión en el escenario profesional se lleva a cabo sólo mediante las prácticas o los contactos puntuales en su futuro sector profesional.

Postulamos que, en la medida en que el estudiante sea iniciado en esta metodología reflexiva durante su etapa universitaria, en esa misma medida 
podrá, en un futuro profesional próximo, ejercitarse como un docente reflexivo que aprende de su propia práctica. Precisamente la capacidad de aumentar su CR se convierte, en el estudiante, en medio que refuerza la calidad del proceso educativo y promueve un aprendizaje adecuado a la enseñanza superior.

Para Barnett (1992), la CR es un medio para estimular a los estudiantes a que desarrollen la capacidad de observarse y de emprender un diálogo crítico con ellos mismos y con todo lo que piensan y realizan; es un procedimiento reflexivo en que el alumno se interroga sobre sus pensamientos o acciones. El resultado deseado del aprendizaje de cada estudiante es el del profesional reflexivo. Este planteamiento formativo, estrechamente ligado a la realidad, se sustenta en una visión constructivista del aprendizaje práctico del estudiante, según la cual el conocimiento sobre la práctica docente debe ser un conocimiento creado por el mismo sujeto en formación, no un conocimiento creado con anterioridad por terceros y transmitido por ellos. El alumno practicante se está formando de un modo real y auténtico, precisamente porque es él quien concede un significado personal a unos contenidos que ahora vive y sobre los que reflexiona y en los que están implicadas muchas dimensiones de su persona.

\section{PROPUESTAS DOCENTES PARA LA FORMACIÓN REFLEXIVA DE LOS ESTUDIANTES}

Resulta relativamente fácil disponerse favorablemente respecto a la formación de estudiantes reflexivos. Sin embargo, la innovación que esto supone en el ámbito de la formación universitaria es notable y este objetivo formativo - que para algunos se percibe aún como un ideal y para otros constituye una realidad- plantea una ruptura considerable con los planteamientos academicistas de larga tradición que laten bajo el quehacer docente de muchos profesores universitarios. La necesidad de un cambio en los modelos de enseñanza-aprendizaje comienza con la compresión de la función docente como acción prioritaria para guiar y orientar el proceso de aprendizaje, mediante la realización de una verdadera acción mediadora entre el alumno y su aprendizaje. 
Se desea cambiar la orientación del aprendizaje hacia formas críticoreflexivas, pero lo que presenta dificultades es volverlo realidad en los actuales currículos de Educación Superior. Se apuntan algunas orientaciones y sugerencias que propician en los estudiantes el desarrollo de la reflexividad y el aprendizaje de la CR en la Universidad, especialmente enmarcado en el espacio curricular del Practicum (prácticas en escenarios profesionales durante toda formación universitaria), que ofrece a los estudiantes una vivencia de su espacio profesional real en las aulas escolares. Estas sugerencias pedagógicas son el resultado de mi propia experiencia docente y del simultáneo estudio de su fundamento teórico.

Conviene señalar que la enseñanza de la capacidad reflexiva, precisamente por su naturaleza, se resiste a un intento de formalización que la encorsetaría e invalidaría su aplicabilidad a otros contextos universitarios. Algunas capacidades pueden ser aplicables a otras titulaciones universitarias y otras son específicas de la preparación para la profesión docente. Enseñar a nuestros alumnos -futuros maestros- a ser reflexivos requiere, en primer lugar, un cambio en el docente, en sus concepciones, sus actitudes, sus planteamientos, sus prácticas, etcétera, que se enumerarán y describirán brevemente a continuación.

\section{Facilitar Situaciones de Aprendizaje}

El papel tradicional del profesor, como transmisor del conocimiento pierde valor, a la vez que adquiere relevancia su nueva función de crear condiciones que faciliten a sus alumnos oportunidades de desarrollo personal y que potencien sus conocimientos, competencias, capacidades y habilidades. Ello origina una «nueva» consideración del profesor como agente (Rué, 2007), es decir, como alguien capaz de actuar deliberadamente, efectuar cambios y responsabilizarse de sus acciones, interviniendo de forma flexible y contextualizada.

Y si el trabajo del docente ya no consiste propiamente en transmitir conocimientos sino en facilitar situaciones de aprendizaje a partir de la práctica, su función principal es la de actuar como facilitador y orientador de los procesos reflexivos que realizan sus alumnos a partir de la práctica. Para asumir esta nueva identidad, el profesor universitario ha de ser 
consciente de la relación potencial entre enseñanza y aprendizaje. Si falta dicha concienciación, el docente acabaría, a largo plazo, apoyándose en ese potencial pero de un modo inconsciente $y$, por tanto, menos fructífero en la formación de los estudiantes. No es aconsejable que el docente efectúe un paso brusco, sino más bien un paso progresivo en el uso de los métodos exclusivamente didácticos a los métodos basados en una estricta autonomía del alumno. Heron (1993) cita tres modalidades de facilitación: la jerárquica, la cooperativa y la autónoma. Sin embargo, no debemos interpretar que la facilitación por parte del docente signifique ausencia de estructura o límites.

Como consecuencia de la interiorización de su nueva función en el aula universitaria, el profesor pondrá al alcance de todo el grupo el conjunto más amplio de recursos posibles para el aprendizaje y se considerará a sí mismo como un recurso flexible para el grupo. Fácilmente el profesor centrará a sus alumnos en actividades con poder transformador, es decir, que propiciará un aprendizaje transformacional aunque no explicite esta intención. Y refiriéndose a esa emergente función, Rué apunta:

La mediación facilita y ayuda a construir y reconstruir el conocimiento del propio alumnado, aportándole experiencias positivas de aprendizaje. Este enfoque de enseñanza potencia un pensamiento reflexivo y no sólo reproductivo, que lleva implícita la utilización de estrategias metodológicas adecuadas a la realidad del aula (Rué, 2002: 56).

Para la formación reflexiva, el docente ha de promover una relación dialógica, un diálogo reflexivo en el que se compromete al alumno hasta el extremo de sus conocimientos, su yo y el mundo. Este diálogo, además, genera una conexión con los otros compañeros que reporta la seguridad necesaria para exponer sus ideas y asegura que el alumno proyecte sus consecuencias para él y para su aprendizaje. Además, la conexión con los otros apoya la perturbación o el trastorno que puede producirse cuando se cuestionan supuestos vigentes y el diálogo eficaz versa sobre el material emocional que fluye a partir de esas cuestiones. La participación con los demás, aunque a veces presente una vertiente dolorosa, puede generar nuevos aprendizajes, forjados en la incomodidad y la lucha del diálogo, que emergen a manera de aprendizaje reflexivo y crítico. Por ello, el 
docente universitario cuenta con el poder del diálogo intencionado para promover y enseñar la CR.

Esta premisa contribuye a combatir la resistencia a considerar la enseñanza como práctica profesional en la enseñanza superior. Y si esta línea es válida para todas las titulaciones, en el caso de los futuros maestros, la presión hacia la orientación práctica se intensifica por ser una profesión de coste práctico y aplicado.

\section{Apertura del Docente a los Contextos del Aprendizaje}

Para facilitar la reflexividad de sus alumnos, los docentes universitarios han de sostener habitualmente una postura más abierta en relación con el contexto del aprendizaje, y de las situaciones, sin limitarse al terreno en que se saben expertos, ocupados en una formación continua. Esta actitud potencia una relación unidireccional con sus alumnos, cuando lo que se necesita más bien es establecer relaciones bidireccionales (profesoralumno) que contribuyan al aprendizaje transformacional en los alumnos. Para enseñar, la CR se ha de ejercitar un verdadero diálogo reflexivo, que exige bidireccionalidad.

Otro buen recurso en esta misma línea es que el profesor aproveche su práctica profesional para el ejercicio docente, así como para su investigación, etcétera. Es preciso que el docente universitario transforme su enseñanza en el aula universitaria abriéndola a nuevos contextos que produzcan cambios e interacciones que sean capaces de acelerar los aprendizajes de sus alumnos y sus motivaciones para obtenerlos.

\section{Transparencia Disciplinar con los Estudiantes}

Otro modo de favorecer el desarrollo reflexivo lo encontramos en la transparente relación de los docentes con sus alumnos. Entre los académicos existe una cierta tendencia a ocultar la lucha intelectual en que están comprometidos en la disciplina escogida por ellos, y sus dilemas correspondientes. El principio de la transparencia requiere que el profesor explicite los procedimientos secretos presentes en el programa, no sólo las tareas. Los alumnos precisan conocer las tareas es decir, qué hay 
que hacer, pero también requieren conocer el procedimiento, es decir, cómo debe realizarse. Este mismo principio, a su vez, ha de aportar claridad sobre las relaciones de poder presentes en las situaciones de aprendizaje y, al hacerlas explícitas, permite a los alumnos adaptar su postura ante ellas, reconociéndolas y familiarizándose con ellas. Barnett plantea que los académicos se presenten como personas, se comprometan con la acción crítica, y se coloquen en una situación que no difiera de la situación de los estudiantes. Este proceso exige:

Valor, integridad y autenticidad, por una parte, y las cualidades de la paciencia, sensibilidad, respeto y reciprocidad intersubjetivos, por otra (Barnett, 1997: 110).

\section{Transferir la Responsabilidad del Aprendizaje}

La maduración de la idea del profesor universitario como facilitador de aprendizaje del alumno - y no de transmisor de conocimientos- lleva a interrogarse sobre la responsabilidad del aprendizaje y sobre en quién debe recaer ésta. El paso de los métodos de transmisión de conocimientos, desde un formato tradicional a los de facilitación del aprendizaje, supone cierta transferencia de responsabilidad del profesor al estudiante, especialmente la concerniente al aprendizaje del alumno que de forma inconsciente suele asumirla el profesor.

Esta transferencia de responsabilidad al alumno ha de hacerse progresivamente y en muchos casos se tratará sólo de una transferencia parcial y que implica una novedad para el alumno, no exenta de inseguridad e incertidumbre (contraria a la costumbre de la clase magistral que sitúa la responsabilidad en el docente y en el grupo, pero no en el alumno individual). Este cambio fácilmente estimula al alumno con elementos emocionales que le llevan a comprometerse y a retarse a sí mismo en su propia capacidad de aprender. Asume riesgos, siente miedo, se aventura a nuevas formas de aprender, y adquiere progresivamente una mayor autonomía y creatividad en su percepción de la realidad y de la práctica educativa. Barnett (1997) realiza una apuesta radical sobre la formación crítico-reflexiva que los docentes han de promover en la enseñanza superior: 
Los académicos se han fijado para sí mismos un conjunto limitado de tareas para desarrollar las capacidades críticas de los estudiantes. [...] la enseñanza superior para la época moderna tiene más misión que generar incertidumbre epistemológica; también debe proporcionar incertidumbre personal y ontológica y tiene que producir una incertidumbre práctica (Barnett, 1997: 175).

Sin embargo, para que ese proceso sea formativo y fructífero requiere una participación considerable del docente que debe dedicar menos tiempo al discurso proposicional y más tiempo a escuchar y orientar personalmente a sus alumnos que han vivido experiencias distintas en contextos escolares variados. El docente reduce el índice de responsabilidad en el aprendizaje del alumno y, simultáneamente, aumenta el índice de responsabilidad en las tareas de supervisión.

\section{Establecer Complicidades Didácticas con los Alumnos}

El docente universitario ha de estar dispuesto a mantener un tipo de relación con sus estudiantes que no responde al modelo tradicional académico. Si estas relaciones han estado marcadas durante siglos por la separación y el aislamiento, ahora se tornan relaciones más próximas, tanto intelectual como afectivamente, entre uno y otro, y también con los propios compañeros de estudios. Las relaciones establecidas son menos fijas, menos estandarizadas, más simétricas y, en ocasiones, novedosas, ya que se sustentan en la facilitación, no en la transmisión jerárquica del saber. Buber (1994) apuesta fuerte por ellas y llega a afirmar que el aprendiz se educa gracias a las relaciones y que la relación que caracteriza el aprendizaje personal es la relación yo-tú que describe así:

La relación es mutua. Mi tú me afecta, como yo le afecto. Estamos moldeados por nuestros alumnos y hechos por nuestras obras [...]. Vivimos nuestras vidas inescrutablemente incluidas en la fluyente vida mutua del universo (Buber 1994: 30). 


\section{Crear Conexiones Emocionales Positivas}

Los docentes universitarios no están habituados a prestar atención a los elementos emocionales del aprendizaje y es fácil que se desentiendan de los sentimientos de sus estudiantes. El pensamiento de sus alumnos no va madurando biológicamente, o biogenéticamente, o psicogenéticamente, sino de forma simultánea y global. El sujeto va construyéndose globalmente a sí mismo a partir de sus percepciones, de la manera en que se le han presentado satisfacciones e insatisfacciones de sus necesidades primordiales, de la calidad de los sentimientos instalados, de su pasado y presente emocionales, etcétera; todos esos elementos vertebrados y entrelazados entre sí van especificando y delimitando sus cogniciones.

Cuando el profesor universitario tiene estima por sus alumnos y está comprometido con ellos, les facilita personalmente la construcción de su propia formación práctica, y les presta el necesario apoyo a nivel emocional. En esta línea se expresa Valls:

La vinculación que se establece entre docente-discente no sólo beneficia la dimensión emocional de esta relación, sino aspectos tan diversos como el aprovechamiento y el control del tiempo, el perfeccionamiento en las tareas, el apoyo en momentos de desconcierto (¿cómo lo hago?, ¿voy bien encaminado?...). El acompañamiento realizado por el profesor ha de permitir que el alumno sea capaz de proponerse objetivos a corto y largo plazo, encontrar soluciones a sus dificultades, descubrir estrategias y recursos que le permitan continuar avanzando en su proceso de aprendizaje. En este contexto, se pueden generar espacios y situaciones que estimulen la creatividad y minimicen los mecanismos de defensa frente al hecho de aprender (Valls, 2008: 34).

Precisamente las situaciones en que se produce el conocimiento están cargadas de reflexiones e intervenciones personales, y los procesos de autoestima son, en estas ocasiones, muy frágiles en función del efecto que producen en los demás. Las relaciones más simétricas con profesor y alumno comportan una mayor vulnerabilidad emocional en el estudiante que se sincera sobre su acción práctica, sus sentimientos y sus reflexiones en la intervención escolar y después de ella. 
Aunque sea obvio, en este marco se precisa recordar que los sentimientos de afecto entre el docente y el practicante contribuyen a crear una actitud positiva hacia el aprendizaje y se comunican a través de actitudes empáticas de paciencia, apoyo a su autoestima, perseverancia, etcétera. En esta línea, apunta Wernicke (1993) que las interacciones son siempre emocionales e intelectuales: no pueden ser una cosa $u$ otra; en toda interacción, cada participante aporta sus propias emociones; pero en ocasiones surge una nueva emoción, ya no propia de cada uno sino de ambos o del grupo: la interacción se ha transformado en relación; nace un vínculo.

El docente se compromete con sus alumnos en el aprendizaje, y la voluntad de ayudarles le conduce a planear y cambiar estrategias, adaptándose a las posibilidades de los estudiantes, incluso cuando éstos sostienen alguna actitud negativa.

Tal como apunta Freire (1996), los profesores enseñan a sus alumnos a querer y a disfrutar del aprendizaje y dan muestra de competencia científica, capacidad de amar, humor, claridad política y coherencia. Relacionan las dificultades y los obstáculos con las facilidades para aprender. Estimulan la curiosidad crítica de los alumnos y no la memorización mecánica de los contenidos transferidos. Para ellos, enseñar y aprender son partes inseparables del mismo proceso de conocer. La función del profesor en la escuela es proporcionar un ambiente que estimule las preguntas y las respuestas que dirigen el curso del pensamiento del alumno. El profesor modifica los estímulos para que la respuesta logre la formación de disposiciones intelectuales y emocionales deseables.

Para expresar este nuevo tipo de relaciones entre docentes y alumnos, Belenky (1996) utiliza la expresión aprendizaje conectado ${ }^{1}$. En resumen, las relaciones necesarias para propiciar la reflexividad en los estudiantes son mutuas y no unidireccionales, abiertas a las diferencias y a la incertidumbre,

1 «En una clase conectada, nadie se excusa por la incertidumbre. Se asume que el pensamiento en evolución es provisional [...] podemos hablar con certeza, pero [...] también podemos intentar construir un tipo de autoridad diferente, basada en la experiencia personal individual y reconociendo las incertidumbres implícitas en un enfoque que valora lo personal (Belenky, 1996: 221). 
y no ligadas a unos resultados inflexibles. La noción de aprendizaje como un proceso social y colaborativo no se acomoda fácilmente al tradicional sistema educativo occidental de corte competitivo, individualista y distante.

\section{Utilizar Metodológicamente el Diálogo Reflexivo}

Una de las aportaciones de la pedagogía contemporánea es el aprendizaje dialógico (Flecha, 1997), planteamiento que enfatiza las interacciones. El diálogo reflexivo e intencionado constituye un elemento clave de la CR cuando está al servicio del aprendizaje y lo interpretamos en nuestro contexto como diálogo didáctico.

Cada vez son más las investigaciones que confirman que el proceso de aprendizaje depende de la coordinación entre las actividades que se llevan a cabo en los diferentes contextos de la vida del estudiante y no sólo en lo sucedido en los espacios y tiempos establecidos para la enseñanza en el aula universitaria. Para ello, el diálogo es capaz de introducir en el aula universitaria esa diversidad de vivencias y de elementos para que el estudiante realice un aprendizaje profundo y significativo desde el punto de vista psicológico.

Sin embargo, conviene señalar que el hecho de que docentes y estudiantes estén comunicándose en el aula universitaria no garantiza que exista un diálogo reflexivo. Diálogo reflexivo y comunicación están estrechamente relacionados si analizamos el contexto del aula universitaria; sin embargo, no significan exactamente lo mismo, aunque percibimos que a nivel didáctico la comunicación y el diálogo ${ }^{2}$ son aliados básicos de la reflexión.

${ }^{2}$ «El diálogo es la mutua comunicación entre dos o más personas, en la que los interlocutores desempeñan el papel tanto de emisores como receptores. [...] en la conversación hay mutua correspondencia, es decir el emisor emite su mensaje que capta el receptor, quien al dar respuesta convierte su contestación en mensaje, que a su vez capta el emisor» (Méndez, 1994: 68). 
La autorreflexión se apoya y complementa en el diálogo con los otros, con el profesor y los compañeros, y ha de incluirse como estrategia didáctica formativa en la Universidad. Precisamente, el diálogo reflexivo conduce al pensamiento reflexivo. Su uso metodológico facilita a los alumnos el paso del llamado "aprendizaje de bucle sencillo» de carácter instrumental, mecánico y previsible, al «aprendizaje de doble bucle», aquel que activa en el estudiante el cuestionamiento de las premisas y promueve el pensamiento crítico, reflexivo y creativo. Esta cuestión requiere que el docente universitario no tema la participación de los alumnos en una situación de clase y que sepa gestionar esas interacciones intelectuales generadas entre teoría y práctica. Buena parte de la función del profesor en ese diálogo con y entre sus alumnos es proporcionar un ambiente que estimule las preguntas y las respuestas que dirigen el curso del pensamiento del alumno. En este sentido (Valls, 2008) conviene tener en cuenta que se debe atribuir un espacio y un tiempo para la reflexión del alumno, que le permita pensar y verbalizar los procesos y las tareas, tanto las realizadas satisfactoriamente como las que no lo fueron. Ello facilita integrar esta realidad en un contexto de verdaderas oportunidades de aprendizaje, permitiendo ajustar la enseñanza a las características singulares de cada alumno. Desde el aprendizaje dialógico la diferencia va unida a la igualdad: igualdad para que todos alcancen el nivel de aprendizaje por el que optan y diferencia para que todos puedan lograrlo sin renunciar a sus propias opciones antropológicas, pedagógicas y educativas, culturales y religiosas, etcétera.

El profesor modifica los estímulos para que la respuesta alcance la formación de disposiciones intelectuales y emocionales favorables.

El diálogo reflexivo que permite el aprendizaje críticamente reflexivo, compromete a la persona hasta el extremo de sus conocimientos, su sentido del yo y del mundo, tal como lo experimentamos. Por tanto, se cuestionan nuestras premisas sobre el saber, sobre nosotros mismos y nuestro mundo. Se cuestionan también las premisas vigentes sobre las ideas, el yo y el mundo (Brockbank, 2002: 73).

La figura central en la organización y desarrollo del proceso educativo recae en el profesor que guía ese diálogo reflexivo; su experiencia, 
motivación e inclusión en la actividad, promueve que sus alumnos construyan y reconstruyan el conocimiento en una atmósfera participativa e indagadora que propicia e induce al estudiante a expresar su mundo interno ${ }^{3}$. La construcción del conocimiento a través del diálogo reflexivo no significa la ausencia absoluta de momentos expositivos por parte del profesor. El profesor es quien promueve el diálogo reflexivo entre docentes y estudiantes garantizando la bidirecccionalidad de la comunicación.

Sin embargo, en este clima de diálogo existe una posible falacia didáctica: cuando las intenciones del profesor consisten en hablar a sus alumnos largo y tendido, en sentido didáctico, con la intención de transmitir su posición o conocimientos en una materia, el diálogo deja de ser reflexivo y bidireccional y pasa a ser unidireccional e incapaz de propiciar en los estudiantes ideas nuevas. Esta forma didáctica de apariencia dialógica, basada en el diálogo unidireccional, se caracteriza por el hecho de que una de las partes reclama para sí el carácter de experto que quiere interactuar con quienes no lo son.

El diálogo que se plantea desde el aprendizaje dialógico es un diálogo igualitario; supone que se funciona a partir de la validez de los argumentos y no de la posición de poder que cada agente ocupa. Cuando se lleva a cabo el diálogo igualitario, el profesorado no ve cuestionado su papel sino que, al contrario, se refuerza. También aumenta su formación ante la necesidad de argumentar sus propuestas.

Conviene advertir que en estas situaciones didácticas el diálogo reflexivo no es amenazador ni para quien enseña ni para quien aprende ${ }^{4}$, es un estímulo y un recurso pedagógico que genera energía para aumentar la significatividad del aprendizaje y para que los alumnos se mantengan activos en ese proceso que no podrá ser transmisivo.

3 Me agrada ilustrar esta consideración con unas palabras que ennoblecen el valor humano de la apertura a los demás: «Un pensamiento que no se expresa, un juicio práctico que no se realiza, son actos infecundos. Incluso el enriquecimiento personal que nace de la especulación teórica, alcanza todo su sentido cuando se comparte» (Ruiz, 1996: 402).

4 Sin embargo en el hábitus y teorías implícitas de numerosos docentes, sí que ese diálogo es percibido inconscientemente como una situación amenazadora de control y dominio en el aula universitaria. 
El diálogo reflexivo entre profesor y alumno, y entre alumnos entre sí, permite reflexionar a los alumnos sobre sus prácticas con el apoyo de los que dialogan con él, y puede, a su vez, influir en su próxima práctica, enriqueciendo con aprendizaje práctico a quienes intervienen en el diálogo colectivo.

El diálogo compartido supera en mucho el diálogo que uno puede establecer consigo mismo. El diálogo reflexivo con los demás sobre una práctica, facilita el abordar los sentimientos del practicante antes, durante y después de la acción, produciendo el fenómeno del descubrimiento de teorías implícitas, elementos inconscientes y elementos emocionales que han interactuado y que se explicitan por medio de la ayuda de los otros, quienes pueden contribuir con su visión más externa y quizás algo más objetiva.

Uno de los espacios más oportunos para el diálogo reflexivo es el Seminario, modelo potencial del desarrollo de la CR del estudiante. Un número reducido de alumnos facilita el clima para ese diálogo entre unos y otros, y la supervisión del docente resulta más asequible y controlable.

\section{Promover la Perspectiva}

\section{Interdisciplinar y Transdisciplinar}

La CR propone al alumno el aprender a partir de su propia práctica en el aula escolar. Y el alumno, al acudir al aula, se introduce en una realidad viva, unitaria, pero de gran complejidad, plena de interacciones, fuertemente contextualizada $y$, en ciertas situaciones, le corresponde intervenir con una respuesta única, que condense y vertebre una enorme cantidad de conocimientos, experiencias, creencias, teorías, etcétera. Urge, por tanto, que la institución universitaria proceda a una mayor transferencia del conocimiento y promueva una perspectiva más interdisciplinar y transdisciplinar. Con ello no fragmenta artificialmente el saber en disciplinas que la realidad profesional no secciona, sino que las presenta profundamente relacionadas y unidas. Si esta sugerencia es, en efecto, de complicada puesta en práctica, una contribución posible de los docentes es abrir sus disciplinas, asignaturas y programas y adoptar actitudes más flexibles que no les limiten a su estricto marco de referencia 
inmediato de su asignatura. Debemos romper el encajonamiento del saber para convertirlo en un saber global. Si el saber no aporta soluciones al contexto multidisciplinar que vivimos, no sirve de nada.

Podemos identificar tres acepciones diferentes del concepto de interdisciplinariedad, de acuerdo con el resultado del informe elaborado como consecuencia del encuentro convocado por la Universidad de Stanford, en agosto de 2002, para tratar de crear un nuevo formato de trabajo universitario:

1) La versión banal, producto de una «complementariedad» entre diferentes disciplinas, normalmente consecuencia de la necesidad de trabajar juntos abordando diferentes aspectos de una misma problemática. Por ejemplo, la relacionada con la cuestión urbanístico-social en las grandes metrópolis. Intervienen y se interponen urbanismo, arquitectura, geografía urbana, sociología, economía, ingeniería, derecho, etcétera. Esta interdisciplinariedad «de fin de semana», es portadora de la convicción de que lo que las otras disciplinas puedan decir, en nada cambiará el trabajo que cada participante realiza. El resultado final es un «informe-sumatoria» donde los criterios de coherencia entre los diferentes «productos» de cada disciplina son poco consistentes.

2) La versión académica, producto del tiempo que algunos investigadores pasan juntos, consecuencia de la obligación establecida por algún financiamiento concedido por instituciones de enseñanza o que se dedican oficialmente a investigaciones «interdisciplinarias». El resultado final es una conversación intelectualizada en la cual cada interlocutor trata de exhibir su trabajo individual, sus hipótesis «innovadoras», su «originalidad».

3) La posibilidad de una verdadera co-elaboración intelectual, relacionada con la puesta en interacción de las diversas disciplinas involucradas, cuyos resultados potenciales no podrían haber sido producidos aisladamente. Para que esto se produzca es necesario que previamente haya sido establecido un terreno común por medio de conceptos fundamentales compartidos. 
Ésta es la dimensión de la interdisciplinariedad que nos interesa integrar en la perspectiva docente de nuestra institución universitaria y por la que apostamos en esta investigación.

La transdisciplinariedad implicaría la intersección de diferentes disciplinas, provocando atravesamientos entre campos capaces de posibilitar múltiples visiones simultáneas del objeto en estudio.

a) Los campos disciplinarios constituyen estructuras y si éstos interaccionan entre sí, producen relaciones. Por ello, el profesor puede utilizar esas posibilidades de intersección entre las disciplinas para los procesos de enseñanza-aprendizaje.

b) Promover la inteligencia general y no parcelaria. Para alcanzar a focalizar la complejidad, superando la fragmentación disciplinaria, hay que avanzar mas allá de la sumatoria de campos que prescinde de las interrelaciones. Interesa, por tanto, que el profesor universitario promueva que sus estudiantes desarrollen este tipo de inteligencia una inteligencia general (Morin), que no pretende simplificar y reducir la complejidad artificialmente.

c) Realismo pluralista. El docente ha de transmitir respeto y aceptación por la estructura compleja de la realidad educativa, objeto de estudio y de práctica, en la que «todo influye en todo». El afán reduccionista de simplificar el análisis y la práctica educativa descalificaría profesionalmente al profesor universitario ${ }^{5}$. Si el aula escolar es una organización versátil, viva, dinámica, abierta, flexible, hay que formar a los estudiantes familiarizándoles con la perspectiva interdisciplinar y

5 En Teoría de Sistemas se conoce con el nombre «Prerrequisito de Ashby», la ley formulada por Luhmann, según la cual sólo la complejidad puede acoger complejidad. Aunque también está en lo cierto Habermas cuando plantea, paradójicamente, que la introducción de nuevos sistemas para reducir complejidad puede, más bien, aumentarla. 
transdisciplinar, y orientarles en esa línea para promover modalidades de acción conjunta que integren esta perspectiva ${ }^{6}$.

d) Los campos disciplinarios precisan incorporar la crítica lógica al mismo tiempo que la perspectiva pragmática. Cada disciplina tiene acceso a una faceta del objeto de estudio y, por eso, es necesario producir agentes capaces de circular entre dos o más campos disciplinarios simultáneamente.

Los saberes han de poder interrelacionarse en la educación superior con apuestas de trabajo coordinado que propicien, en el alumno practicante, una mejor comprensión de la realidad vivida durante sus prácticas en la escuela, ecosistema de gran complejidad. Sólo tras una mejor comprensión de la situación educativa, la intervención del alumno en el aula articulará más y mejor las distintas disciplinas implicadas en las situaciones educativas (psicología educativa, didáctica, sociología, etcétera). La CR tiene como objetivo coparticipar y hacer dialogar entre sí estos diversos saberes.

En esta línea, en nuestra universidad ${ }^{7}$ se ha formalizado el Practicum de cada curso de Magisterio desde una perspectiva interdisciplinar e intradisciplinar implicando, en el Practicum de cada curso, el mayor número posible de asignaturas troncales $\mathrm{u}$ obligatorias, recientemente cursadas por el estudiante, con el trabajo cooperativo de los profesores implicados.

\section{Enfocar el Aprendizaje desde la Perspectiva Holística}

Si la formación del futuro maestro ha de orientarse a la práctica, uno de los modos de prepararle para su quehacer docente es propiciar, durante

6 Todo docente universitario es consciente de la complejidad que plantea la realidad educativa, pero en ocasiones se evita la perspectiva interdisciplinar por motivos más bien psicológicos, puesto que abrirse a las relaciones interdisciplinarias genera inseguridad intelectual y desafíos que se presentan como amenazas a la sensación de dominio sobre un programa o disciplina cerrado, y el docente puede temer esa pérdida de control, en la que se apoya su poder y autoridad.

Universidad Internacional de Cataluña, España. Nota del editor. 
su formación inicial, un modo de pensar de carácter analógico que le ayude a lograr que su mirada intelectual hacia el objeto de estudio capte las diferencias sin perder la unidad. El Diccionario de la Real Academia Española define el holismo como «la doctrina que propugna la concepción de cada realidad como un todo distinto de la suma de las partes que lo componen». En este contexto surgen las llamadas sinergias, ese efecto añadido positivo producido al unir dos o más unidades, y que es superior cualitativamente a la estricta suma. La perspectiva holística ${ }^{8}$ - a veces asimilada a la naturalista - se nutre conceptualmente de la investigación etnográfica y se la enmarca en la filosofía de la totalidad ${ }^{9}$. Propone una visión global de la realidad estudiada, integrando toda su complejidad desde distintos puntos de vista, internos y externos, objetivos y subjetivos, y en la que interesan las interpretaciones de todos los implicados en el estudio de las temáticas.

Es la perspectiva más coherente con la interdisciplinariedad y la transdisciplinariedad. Este enfoque del conocimiento implica a todos sus componentes con sus relaciones obvias e invisibles. Normalmente se emplea como una tercera vía o nueva solución a un problema. El holismo enfatiza la importancia del todo, que es distinto que la suma de las partes (propiedad de sinergia) y otorga importancia a la interdependencia de éstas.

La psicología cognitiva suele llamar holístico a aquel estilo de aprendizaje que estudia el todo, relacionando sus partes, pero sin separarlo absolutamente, en palabras del profesor Wernicke ${ }^{10}$ :

8 El holismo (del griego holos que significa todo, entero, total) es la idea de que todas las propiedades de un sistema (biológico, químico, social, económico, mental, lingüístico, etcétera) no pueden ser determinadas o explicadas como la suma de sus componentes. El sistema completo se comporta de un modo distinto que la suma de sus partes.

9 Esta característica, propia de la investigación etnográfica, propone una visión global de la realidad estudiada, integrando toda su complejidad desde distintos puntos de vista. Esto la hace más rica en significados sociales, ya que reproduce distintas perspectivas.

${ }^{10}$ Este profesor argentino, procedente del ámbito médico, dirige actualmente la Fundación Holismo de educación, salud y acción social, dedicada a extender la perspectiva holística en las ciencias y en los planteamientos prácticos de la pedagogía, formación de docentes, la atención de pacientes y la atención de problemas sociales. Más información, disponible en: [http:/ / www.holismo.com.ar/]. 
El paradigma general del sujeto será holístico cuando reconozca la construcción mental de un sistema de mapas globales y fragmentarios, como formas de captación y organización de la realidad, con interpretación simultánea desde diversas dimensiones, la inevitable interacción entre todos los mapas (integración) y un constante desarrollo dinámico objetual-fenoménico y subjetivo (Wernicke, 2003: 168).

En cambio, un paradigma fragmentario supone la falta de interacción entre las distintas dimensiones del ser humano y la división estricta entre los distintos mapas, sin una supuesta influencia recíproca de éstos entre sí. A la perspectiva holística se opone la serialista. John S. Daniel diferencia así estas dos tipologías de aprendizajes diferentes:

a) Aprendizaje serialista: Aquél en que se aprende paso a paso, creando nuevas hipótesis a medida que avanzan y «a quienes los árboles no dejan ver el bosque» (Daniel, 1975: 85). Cuando se les pide que enseñen lo aprendido, los serialistas reproducen el procedimiento con exactitud. Este aprendizaje se aproxima al concepto de enseñanza como reproducción.

b) Aprendizaje holístico: Aquél en que se aprende globalmente, apreciando la complejidad y el marco completo. Cuando se les pide que enseñen lo aprendido, los aprendices holistas cambian el orden y saltan de unas cosas a otras, aunque sin perder la coherencia y el sentido. En este caso, el planteamiento de la enseñanza se entiende como transformación.

Estudiadas las diferencias entre el holismo y el serialismo, debemos apuntar que para lograr que los estudiantes sean capaces de activar su capacidad reflexiva se requiere que sus profesores los familiaricen con esta perspectiva, promoviendo estrategias de aprendizaje holístico y evitando que su aprendizaje se estructure de una forma lineal, plana y atomizada.

Precisamente el espacio curricular del Practicum, favorece esta percepción holística de la realidad educativa y contribuye a que el estudiante, a medida que avanza en su proceso formativo, establezca 
relaciones cognitivas y experienciales -interdisciplinares e intradisciplinares- a partir de sus prácticas y que éstas, siendo crecientes, abiertas y creativas, conduzcan a una síntesis profesionalizadora en su saber, su saber hacer y su saber estar.

Estas propuestas se sustentan en varias investigaciones que llegan a la misma conclusión por diferentes itinerarios. El enfoque atomista del aprendizaje se centra en los detalles, aislados o en sucesión, recordando la secuencia serialista. Los enfoques holistas u holísticos hacen hincapié en los significados globales y tratan de contextualizar el material nuevo en lo que ya se conoce, buscando los argumentos clave o principales (Svensson, 1997). Los programas pensados para aprendices atomistas revelaban que los alumnos pueden modificar su enfoque o concepción del aprendizaje cuando se les facilita un ambiente que apoye ese paso (Saljo, 1979).

Y caminando un paso más en la línea expuesta, considero necesario no someter a un estudio parcelario y fragmentado las situaciones que el practicante vive en el aula. Son vivencias que acumulan muchos elementos e interacciones ricas y complejas, latentes en el aula escolar y que la realidad presenta al practicante de forma global y unitaria. Como consecuencia, es preciso que los alumnos, al reflexionar sobre su práctica, lo hagan también de forma holística. Según Dewey (1989), la reflexión no consiste en un conjunto de pasos o procedimientos específicos que han de seguir sistemáticamente los profesores. Es, en cambio, una forma de afrontar y responder a los problemas. La acción reflexiva constituye un proceso más amplio que el de la solución racional de los problemas. La reflexión implica intuición, emoción y pasión: no es algo que pueda acotarse de manera precisa, como han tratado de hacer algunos, y enseñarse como un conjunto de técnicas para uso de los maestros.

Por tanto, para enseñar al practicante a ejercitarse en la CR, inicialmente habrá de efectuarse con una etapa de uso sistemático de un modelo o metodología que sistematice su reflexión y que guíe en estos procesos reflexivos a los que está poco habituado. Una vez superada la inseguridad e incertidumbre iniciales, el practicante adquiere soltura y ya no se precisa el seguimiento ordenado y sistemático de la metodología; 
así, empleará el método de forma flexible, abierta, sin límites, en definitiva, su CR irá adquiriendo una clara orientación holística.

\section{Estrategias y Técnicas para Inducir a la Reflexividad}

En su tarea de planificación, el docente ha de definir qué estrategias de enseñanza-aprendizaje se adecuan mejor a su contexto universitario y cuáles facilitan la iniciación, el entrenamiento y desarrollo de la CR de los estudiantes.

El planteamiento docente que más favorece el aprendizaje reflexivo - y como consecuencia, la CR- es la utilización de metodologías activas y participativas por parte del alumno. El estudiante ha de ser el protagonista de su aprendizaje. Entendemos por pedagogía activa aquella que induce a los aprendices a estar activos intelectual y mentalmente, no sólo cinestésicamente.

Nos limitaremos a enumerar ciertas estrategias de aprendizaje, dinámicas de trabajo y algunos sistemas de evaluación universitarios que facilitan los procesos reflexivos en los alumnos:

- Diario reflexivo individual y grupal.

- Registro de experiencias.

- Diálogo reflexivo.

- Carpetas de aprendizaje o portafolios.

- Trabajo colaborativo entre alumnos.

- Enseñanza de técnicas de observación sistemática.

- Estudio de casos prácticos.

- Reconstrucción mental y verbal de situaciones escolares.

- Auto-informe.

- Ejercicios de inferencia teórica a partir de casos particulares.

- Resolución de casos de intervención educativa.

- Reflexión compartida en los Seminarios de Practicum.

- Verbalización y narración de experiencias reales.

- Detección y análisis de teorías implícitas del docente que han influido.

- Detección metacognitiva de vacíos teóricos a cubrir con formación.

- Auto-evaluación y hetero-evaluación entre los practicantes. 
- Utilización de la indagación como investigación.

- Utilización didáctica de la confrontación o conflicto cognitivo ${ }^{11}$.

- Interacción consigo mismo, con los demás y con la teoría.

Las diez orientaciones expuestas a través de las cuales el profesor universitario puede propiciar el desarrollo de la reflexividad, aunque son asequibles suponen cierta innovación por parte del docente. Mi experiencia al aplicarlas experimentalmente en el marco de mi investigación doctoral es que han mostrado su efectividad de un modo relevante.

${ }^{11}$ Trasladar al aula universitaria la confrontación inicial entre teoría y práctica producida frecuentemente en los estudiantes al entrar en contacto con el escenario profesional, constituye una situación de alto valor formativo que interpela su CR y les conduce a recodificar y reelaborar su conocimiento. 


\section{BIBLIOGRAFÍA}

BARNETT, R. (1992), Improving Higher Education, Buckingham: SRHE / Open University Press.

BARNETT, R. (1997), Higher Education: A Critical Businss, Buckingham: SRHE/ Open University Press.

BROCKBANK, A. y MCGILL I. (2002), Aprendizaje reflexivo en la educación superior, Madrid, Morata.

BUBER, M. (1995), Yo y Tú, Madrid, Caparrós editores (1995, 2ª ed.)

DEWEY, J. (1938), Logic: The Theory of Inquiry, Nueva York, Henry Holt.

DEWEY, J. (1947), Experiencia y educación, Buenos Aires, Losada.

DEWEY, J. (1989), Cómo pensamos. Nueva exposición de la relación entre pensamiento reflexivo y proceso educativo, Barcelona, Paidós.

DOMINGO, A. (2007), «Hacia un modelo holístico del Practicum en el marco del EEES» en CID, A. (coord.). Buenas Prácticas en el Practicum, Santiago de Compostela, USC.

FLECHA, R. (1997), Compartiendo palabras, Barcelona. Paidós.

FREIRE, P. (1996), La educación como práctica de la libertad, Madrid, Siglo XXI (9a ed.).

MORIN, E. (2000), Les sept savoirs nécessaires à l'education du futur, Paris, Seuil.

PERRENOUD, PH. (2004), Desarrollar la práctica reflexiva en el oficio de enseñar, Barcelona, Graó.

SVENSSON, L. (1977), «On qualitative differences in learning IIIstudy skyll and learning», in British Journal of educational Psycology, 47, p. 233-243.

WERNICKE, C.G. (2003), «Una pedagogía contextual», en Educare, IV, Universidad Nacional de Costa Rica, p. 141-155. 